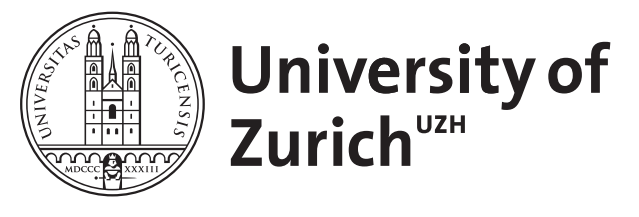

\title{
Safe paediatric intensive care
}

\author{
Frey, Bernhard ; Argent, Andrew
}

\begin{abstract}
Neonatal and paediatric intensive care has improved the prognosis for seriously sick infants and children. This has happened because of a pragmatic approach focused on stabilisation of vital functions and immense technological advances in diagnostic and therapeutic procedures. However, the belief that more medical care must inevitably lead to improved health is increasingly being questioned. This issue is especially relevant in developing countries where the introduction of highly specialised paediatric intensive care may not lead to an overall fall in child mortality. Even in developed countries, the complexity and availability of therapeutics and invasive procedures may put seriously ill children at additional risk. In both developing and industrialised countries the use of safe and simple procedures for appropriate periods, particular attention to drug prescription patterns and selection of appropriate aims and modes of therapy, including non-invasive methods, may minimise the risks of paediatric intensive care
\end{abstract}

DOI: https://doi.org/10.1007/s00134-004-2295-4

Posted at the Zurich Open Repository and Archive, University of Zurich

ZORA URL: https://doi.org/10.5167/uzh-156120

Journal Article

Published Version

Originally published at:

Frey, Bernhard; Argent, Andrew (2004). Safe paediatric intensive care. Intensive Care Medicine, 30(6):1041-1046.

DOI: https://doi.org/10.1007/s00134-004-2295-4 


\section{Bernhard Frey Andrew Argent}

\section{Safe paediatric intensive care

\author{
Part 1: Does more medical care lead \\ to improved outcome?
}

Received: 16 September 2003

Accepted: 23 March 2004

Published online: 22 April 2004

(C) Springer-Verlag 2004

B. Frey (

Department of Intensive Care and Neonatology,

University Children's Hospital, 8032 Zurich, Switzerland e-mail: Bernhard.Frey@kispi.unizh.ch

Tel.: +41-1-2667359

Fax: +41-1-2667168

A. Argent

Paediatric Intensive Care Unit, Red Cross War

Memorial Children's Hospital, Rondebosch, 7700 Cape Town, South Africa

\begin{abstract}
Neonatal and paediatric intensive care has improved the prognosis for seriously sick infants and children. This has happened because of a pragmatic approach focused on stabilisation of vital functions and immense technological advances in diagnostic and therapeutic procedures. However, the belief that more medical care must inevitably lead to improved health is increasingly being questioned. This issue is especially relevant in developing countries where the introduction of highly specialised paediatric intensive care may not lead to an overall fall in child mortality. Even in de-
\end{abstract}

veloped countries, the complexity and availability of therapeutics and invasive procedures may put seriously ill children at additional risk. In both developing and industrialised countries the use of safe and simple procedures for appropriate periods, particular attention to drug prescription patterns and selection of appropriate aims and modes of therapy, including non-invasive methods, may minimise the risks of paediatric intensive care.

Keywords Paediatrics - Safety · Critical incidents $\cdot$ Organisation

\section{Introduction}

Does more medical care lead to improved outcome in the context of critically ill children? In rural Papua New Guinea, the introduction of oxygen for the treatment of severe pneumonia resulted in a major decrease in childhood mortality [1]. In developing countries the introduction of highly specialised paediatric intensive care may not lead to a drop in child mortality if scarce financial and human resources are thereby channelled away from improved quality of paediatric care in rural and district hospitals [2, 3].

Even within developed countries, the "law of diminishing returns" suggests that, after a certain point, additional inputs may provide decreasing additional benefit and that there may be a point at which additional growth will actually cause harm [4]. The paediatric intensivist has the choice of an increasing range of diagnostic and therapeutic techniques, both invasive and non-invasive. While increased diagnostic capacity may improve patient care, it may cause harm by: identifying abnormalities that are not actually causing problems; pressurising clinicians to treat conditions that are asymptomatic; confusing clinicians by the complexity of the diagnoses and by channelling resources away from other clinically relevant issues. Likewise, while increased therapeutic capacity may improve patient care, it may also be associated with increased iatrogenic disease and inappropriate utilisation of scarce resources. Increased complexity of care alone may be responsible for increased numbers of critical incidents, as physicians are more likely to miss important issues and the system becomes more liable to error. Neonatal and paediatric intensive care is especially vulnerable in regard to unintended consequences of care because the wide range of diseases and ages makes standardised care difficult. Anonymous, voluntary critical incident monitoring has shown the dimension of the problem [5] and in paediatric intensive care patients receiving the most intensive and invasive care are especially prone to critical incidents [5]. 
From the early days of paediatric and neonatal intensive care serious side effects were associated with new invasive therapies. In 1967 Northway et al. [6] described a new "pulmonary disease following respirator therapy" in neonates, which was later called bronchopulmonary dysplasia. Oxygen toxicity and baro- or volu-trauma associated with mechanical ventilation were shown to aggravate lung injury [7], partly related to the therapeutic goal of "normal" levels of oxygenation and ventilation.

Even generally accepted therapies have been shown to be harmful. Exchange transfusions for a bilirubin of more than $20 \mathrm{mg} / \mathrm{dl}$ were routinely undertaken in neonatal units until the practice was reviewed [8]. Steroid treatment for chronic lung disease of the newborn was almost routine until recent associations with neurodevelopmental outcome [9]. Even routine postoperative fluid management may be deleterious [10]. The "normal" fluid maintenance volumes used in many paediatric units are based on Holliday and Segar's work [11] and these volumes may be inappropriately high in sick children who have much lower caloric intake, lower urinary excretion rates and decreased insensible losses.

The use of invasive monitoring has facilitated the development of paediatric and neonatal intensive care. However, there are problems in assessing the exact riskbenefit ratio of many invasive interventions, e.g. pulmonary artery catheters [12]. Invasive monitoring may be inappropriate and actually harm patients. In a paediatric intensive care unit, routine use of invasive monitoring of infants with respiratory syncytial virus disease was associated with increased laboratory testing, over-treatment and significant increases in costs and morbidity without improvement in outcome [13]. Similarly, Earle et al. [14] showed that tracheal intubation and the use of central venous catheters were associated with poor outcome for low-risk patient groups in six ICUs in Central and South America. In an adult intensive care unit, the presence of an arterial line led to increased blood drawing [15] and in a neonatal intensive care unit the presence of arterial catheters increased the frequency of blood transfusions, thereby exposing neonates to, probably, unnecessary risk [16].

Even "safety systems" may add to risks: the increasing number of alarm systems in intensive care may be problematic. It has been shown that over 94\% of alarms triggered in a paediatric intensive care unit are not clinically important and may distract care givers from real problems [17].

The clinical examples given above illustrate the possibility of harm from increased medical care. Problems in system structure may also cause harm as reflected by medication errors, which are a leading cause of iatrogenic complications in neonatal and paediatric intensive care [18]. The risks of neonatal and paediatric intensive care may be minimised using several approaches, as discussed below.

\section{Use of safe and simple procedures for appropriate periods}

Most of the success of neonatal and paediatric intensive care is based on an uncompromising, resolute approach to the child with overt or potential respiratory, circulatory or central nervous system failure. The first goal of this pragmatic approach is to stabilise the vital parameters of the seriously ill child according to the $\mathrm{ABC}$ concept (A: airway, B: breathing, C: circulation) [19].

Some questions still remain with this pragmatic approach: Should oxygen be used for the resuscitation of neonates [20]? What is the end point for volume resuscitation in children with trauma and potential bleeding? Recent experimental data challenge the approach of providing aggressive blood pressure support under these circumstances [21]. Although intubation is said to be the gold standard for airway control in children with head trauma, there is data to suggest that urgent prehospital intubation does not improve outcome and may lead to complications [22, 23].

Diagnostic and therapeutic methods must be as safe, simple, standardised and effective as possible. The procedures should be performed by suitably trained and experienced personnel. Adult data have shown that the risks of central venous access are substantially increased if the operator has less personal experience of the technique [24]. This is likely to be true in children, too.

Once invasive techniques have been instituted, they should be terminated as soon as possible. The evidence in favour of such an approach has been shown for tracheal intubation and central venous catheterisation. Complications of endotracheal intubation and mechanical ventilation in infants and children are related to duration [25]. The fact that $47-78 \%$ of neonatal and paediatric patients who have had unplanned extubations do not require reintubation $[25,26,27,28,29,30]$ suggests that ventilation is frequently being prolonged unnecessarily. This may be partly due to the association of failed extubation with subsequent prolonged mechanical ventilation [31]. With the use of central venous lines, vascular thrombosis [32] and line-related infections [33] are major complications that are related to the duration of placement.

\section{Particular attention to medication prescription patterns}

Clinicians have become increasingly aware of unnecessary medication and the potential to harm patients. This has been clearly shown for antibiotic use in neonatal and paediatric intensive care [34]. In addition to the danger to the patient to whom they are given, unnecessary antibiotics are potentially dangerous to other patients because of the development of multi-resistant organisms. 
The number of medications given to a patient simultaneously has to be restricted because drug/drug-interactions are not foreseeable even when relatively few medications are prescribed. Furthermore, there is potential to treat side effects of drugs with the application of more drugs.

In paediatric intensive care, drug therapy is especially prone to incidents $[18,35,36,37,38,39,40,41]$, but amenable to organisational measures for improvement. The drug delivery process comprises three stages and errors may occur at each stage: prescription (wrongly or illegibly prescribed or incorrectly transcribed onto the medication chart, calculation errors and confusions of units), preparation and administration. In administration of the drug there may be problems with interpretation of wrong or misleading drug labels or packaging [35]. The following error types may then occur: dose too high or too low, drug omitted or given too frequently, wrong route of administration and wrong drug [35].

In this multi-stage process, interception plays an important role [35]. In order to improve their controlling function, nurses should have drug booklets and perform double checks on selected drugs. Furthermore, involving pharmacists in reviewing drug orders has been shown to significantly reduce the potential harm resulting from errant medication orders [38, 42]. Computerised physician order entry with clinical decision support systems has been shown to reduce the rate of errors [43, 44]. Prescriptions written on a computer can be forced to be legible and complete and applications can force constraints on clinicians' choices regarding the (weight-dependent) dose or route of administration. Using such a system, a physician cannot enter an order for a lethal overdose of a drug.

Given the number of drugs and the number of doses administered to critically ill patients, error limits will have to be considerably below $1 \%$ to avoid significant numbers of daily errors. That requires a very well structured and monitored system.

\section{Selection of appropriate aims of therapy}

One of the problems of therapy has been the delineation of the required end point and the cost of reaching that end point. In paediatric cardiac surgery there has been an evolution away from maintaining blood pressure to optimising cardiac output and decreasing cardiac work. It is likely that that sort of issue will arise in many other areas of paediatric intensive care.

Physiological (healing) processes should be integrated in treatment plans. In neonatal ICU the "minimal handling" concept has been shown to be more successful than more aggressive approaches [45]. Whenever possible, natural organ functions should be maintained. Enteral feeding is considerably safer (and cheaper) than intrave- nous alimentation [46]. Spontaneous breathing is preferable to muscle relaxation/fully mechanical respiratory support whenever possible. The drawbacks of neuromuscular blocking agents include a fall in lung compliance and functional residual capacity, a rise in airways resistance [47], a reduction of joint mobility in premature infants [48] and an association with the so-called critical illness neuropathy [49].

The maintenance of normal body temperature has often been an end point for the use of paracetamol. Some studies now suggest that fever may have a beneficial role in infection [50], and the World Health Organisation recommends that antipyretics be withheld in bacterial sepsis [50].

\section{Selection of appropriate modes of therapy including non-invasive therapeutic and diagnostic methods}

The application of early continuous positive airway pressure (CPAP) by nasal prongs in babies with respiratory distress syndrome (RDS) has been associated with a reduction in the requirement for mechanical ventilation and in its complications [51], although the technique does not improve the outcome with respect to mortality [52].

The World Health Organisation recommends the use of nasal prongs and nasopharyngeal catheters as a safe and efficient means of oxygen administration [53]. It has been shown that these methods, applied to infants with oxygen flows of $0.5-1.0 \mathrm{l} / \mathrm{min}$, produce PEEP of up to $4 \mathrm{cmH}_{2} \mathrm{O}[54,55]$. These levels of PEEP are safe (although gastric distension is a potential complication if the oxygen is poorly administered [56]) and a welcome byproduct because they may contribute to an improvement in oxygenation by altering the viscoelastic properties of the lung. The attributes "safe" and "efficient" are especially important in countries with limited resources for patient monitoring, equipment and supplies, such as medical oxygen. However, safe and simple methods are equally useful in the industrialised world as they have the potential to reduce the risks of therapy.

Gentler modes of ventilation have been successfully introduced. With conventional ventilation, a high-PEEPsmall-tidal-volume-strategy has shown reduced mortality due to acute respiratory distress syndrome in adults [57, 58]. High frequency ventilation, the extreme of small tidal volume ventilation, has been shown to be effective in preventing chronic lung disease in preterm infants suffering from neonatal respiratory distress syndrome [59, 60]. Non-invasive positive pressure ventilation by either a nasal or oral-nasal mask is increasingly used in children with acute respiratory failure [61]. However, it has not been established whether non-invasive positive pressure ventilation can significantly decrease mortality or the incidence of endotracheal intubation in paediatric patients [61]. Non-invasive negative pressure ventilation is not 
widely used, because of lack of portability and limited physical access for nursing care [61].

Advances in medical technology have made it possible to replace an increasing number of invasive, and thus potentially harmful, monitoring devices by non-invasive methods: pulse oximetry, transcutaneous $\mathrm{PO}_{2}$ and $\mathrm{PCO}_{2}$, capnography, continuous electrocardiography to monitor heart rate and inductance respiratory plethysmography to monitor respiratory rate, oscillometric blood pressure measurement (Dinamap) and cerebral function monitoring (continuous EEG with a reduced number of electrodes and combined with a slow chart recorder [62]). Still in the research stage and not yet used in daily clinical practice are: near-infrared spectroscopy to calculate cerebral blood flow [63] and transesophageal Doppler ultrasonography to measure cardiac output [64]. Advances in bedside laboratory equipment enable us to investigate an increasing number of parameters in minimal blood volumes. As an example, capillary whole blood lactate measurements (amperometric lactate biosensor, blood volume $0.04 \mathrm{ml}$ ) in healthy and sick newborn babies agree excellently with arterial values [65]. Therefore, even in very small newborn infants, reliable lactate values can be easily obtained.

Pulse oximetry has become one of the most valuable monitoring techniques in intensive care, anaesthesia and emergency medicine for continuous evaluation of arterial haemoglobin oxygen saturation. In addition, it measures pulse rate, thus providing a non-electrical assessment of the patient's heart rate [66], which may be important when monitoring a pacemaker-dependent child who is at risk of respiratory failure or loss of pacemaker capture. In addition to the above-mentioned parameters, the ampli- tude of the plethysmograph waveform may reflect the adequacy of peripheral perfusion [67] and the amplitude of the plethysmographic respiratory wave reflects variation in intrathoracic pressure and can thus be used for continuous, non-invasive monitoring of pulsus paradoxus [68]. In infants and children at risk of pericardial tamponade, continuous monitoring of the plethysmographic pulse oximeter wave may alert the clinician when increasing respiratory-dependent fluctuations occur [69].

\section{Appropriate staffing}

Despite all the advantages of non-invasive monitoring delineated above, one has to ask the question: what is the evidence that the use of all the technology is any better than trained clinical monitoring? An indication of the importance of the presence of appropriately trained nursing and medical staff who frequently and thoroughly examine patients, has been given in critical incident monitoring. The most important method of critical incident detection was patient inspection; the rate of alarms drawing staff's attention to a critical incident was astonishingly low in view of the high numbers of monitors in use (percentage of critical incidents detected by alarms: $10 \%$ in [5] and $8 \%$ in [70]).

In resource-rich, and resource-constrained communities, there may be a tendency to try and use equipment as a means to limit expenditure on personnel. There is no evidence that ICU equipment can replace trained staff and increasing evidence that understaffing is associated with poor outcome.

\section{References}

1. World Health Organisation (1993) Oxygen therapy for acute respiratory infections in young children in developing countries. World Health Organisation, Geneva WHO/ARI 93.28

2. King M (1993) Demographic entrapment. Trans R Soc Trop Med Hyg 87:S23-28

3. Duke T (2003) Transport of seriously ill children: a neglected global issue (editorial). Intensive Care Med 29:14141416

4. Fisher ES, Welch HG (1999) Avoiding the unintended consequences of growth in medical care. JAMA 281:446-453

5. Frey B, Kehrer B, Losa M, Braun H, Berweger L, Micallef J, Ebenberger M (2000) Comprehensive critical incident monitoring in a neonatal-pediatric intensive care unit: experience with the system approach. Intensive Care Med 26:69-74
6. Northway WH, Rosan RC, Porter DY (1967) Pulmonary disease following respirator therapy of hyaline membrane disease: bronchopulmonary dysplasia. N Engl J Med 276:357-368

7. Dreyfuss D, Saumon G (1998) Ventilator-induced lung injury. Am J Respir Crit Care Med 157:294-323

8. Newman TB, Maisels MJ (1992) Evaluation and treatment of jaundice in the term newborn: a kinder, gentler approach. Pediatrics 89:809-818

9. Vohr BR, Wright LL, Dusick AM, Mele L, Verter J, Steichen JJ, Simon NP, Wilson DC, Broyles S, Bauer CR, Delaney-Black V, Yolton KA, Fleisher BE, Papile LA, Kaplan MD (2000) Neurodevelopmental and functional outcomes of extremely low birth weight infants in the National Institute of Child Health and Human Development Neonatal Research Network, 1993-1994. Pediatrics 105:1216-1226
10. Shafiee MA, Bohn D, Hoorn EJ, Halperin ML (2003) How to select optimal maintenance intravenous fluid therapy. QJM 96:601-610

11. Holliday MA, Segar WE (1957) The maintenance need for water in parenteral fluid therapy. Pediatrics 19:823832

12. Kaye W (1983) Invasive monitoring techniques: arterial cannulation, bedside pulmonary artery catheterization and arterial puncture. Heart Lung 12:395-427

13. Willson DF, Jiao JH, Hendley O, Donowitz L (1996) Invasive monitoring in infants with respiratory syncytial virus infection. J Pediatr 128:357-362 
14. Earle M Jr, Marinez Natera O, Zaslavsky A, Quinones E, Carrillo H, Garcia Gonzalez E, Torres A, Marquez MP, Garcia-Montes J, Zavala I, GarciaDavila R, Todres ID (1997) Outcome of pediatric intensive care at six centers in Mexico and Ecuador. Crit Care Med 25:1462-1467

15. Low LL, Harrington GR, Stoltzfus DP (1995) The effect of arterial lines on blood-drawing practices and costs in intensive care units. Chest 108:216-219

16. Bednarek FJ, Weisberger S, Richardson DK, Frantz ID, Shah B, Rubin LP (1998) Variations in blood transfusions among newborn intensive care units. J Pediatr 133:601-607

17. Lawless ST (1994) Crying wolf: false alarms in a pediatric intensive care unit. Crit Care Med 22:981-985

18. Raju TN, Kecskes S, Thornton JP, Perry M, Feldman S (1989) Medication errors in neonatal and paediatric intensive care units. Lancet 2:374-376

19. American Heart Association (1997) Pediatric advanced life support. American Heart Association, Dallas, Texas

20. Ramji S, Ahuja S, Thirupuram S, Rootwelt T, Rooth G, Saugstad OD (1993) Resuscitation of asphyxic newborn infants with room air or $100 \%$ oxygen. Pediatr Res 34:809-812

21. Pepe PE, Mosesso VN Jr, Falk JL (2002) Prehospital fluid resuscitation of the patient with major trauma. Prehosp Emerg Care 6:81-91

22. Cooper A, DiScala C, Foltin G, Tunik M, Markenson D, Welborn C (2001) Prehospital endotracheal intubation for severe head injury in children: a reappraisal. Semin Pediatr Surg 10:3-6

23. Gausche M, Lewis RJ, Stratton SJ (2000) Effect of out-of-hospital pediatric endotracheal intubation on survival and neurological outcome: a controlled clinical trial. JAMA 283:783-790

24. Sznajder JI, Zveibil FR, Bitterman H, Weiner P, Bursztein S (1986) Central vein catheterization. Failure and complication rates by three percutaneous approaches. Arch Intern Med 146:259261

25. Rivera R, Tibballs J (1992) Complications of endotracheal intubation and mechanical ventilation in infants and children. Crit Care Med 20:193-199

26. Black AE, Hatch DJ, Nauth-Misir N (1990) Complications of nasotracheal intubation in neonates, infants and children: a review of 4 years' experience in a children's hospital. Br J Anaesth 65:461-467

27. Frank BS, Lewis RJ (1997) Experience with intubated patients does not affect the accidental extubation rate in pediatric intensive care units and intensive care nurseries. Pediatr Pulmonol 23:424-428
28. Hagner MJ, Woods K, Pyles L (1994) Inadvertent extubation in PICU. Crit Care Med 22:A154

29. Little LA, Koenig JC, Newth CJ (1990) Factors affecting accidental extubations in neonatal and pediatric intensive care patients. Crit Care Med 18:163-165

30. Metz RI, Mickell JJ (1993) Unplanned extubation in pediatric patients: incidence and related factors. Crit Care Med 21:S155

31. Harrison AM, Cox AC, Davis S, Piedmonte M, Drummond-Webb JJ, Mee RB (2002) Failed extubation after cardiac surgery in young children: prevalence, pathogenesis, and risk factors. Pediatr Crit Care Med 3:148-152

32. Andrew M, David M, Adams M, Kaiser A, Anderson R, Barnard D, Bernstein M, Brisson L, Cairney B, DeSai D (1994) Venous thrombo-embolic complications (VTE) in children: first analyses of the Canadian Registry of VTE. Blood 83:1251-1257

33. Pearson ML (1996) Guideline for prevention of intravascular-device-related infections. Infect Control Hosp Epidemiol 17:438-473

34. Fischer JE, Ramser M, Fanconi S (2000) Use of antibiotics in pediatric intensive care and potential savings. Intensive Care Med 26:959-966

35. Frey B, Buettiker V, Hug MI, Waldvogel K, Gessler P, Ghelfi D, Hodler C, Baenziger O (2002) Does critical incident reporting contribute to medication error prevention? Eur J Pediatr 161:594-599

36. Wilson DG, McArtney RG, Newcombe RG, McArtney RJ, Gracie J, Kirk CR, Stuart AG (1998) Medication errors in paediatric practice: insights from a continuous quality improvement approach. Eur J Pediatr 157:769-774

37. Bordun LA, Butt W (1992) Drug errors in intensive care. J Paediatr Child Health 28:309-311

38. Folli HL, Poole RL, Benitz WE, Russo JC (1987) Medication error prevention by clinical pharmacists in two children's hospitals. Pediatrics 79:718-722

39. Kaushal R, Bates DW, Landrigan C, McKenna KJ, Clapp MD, Federico F, Goldmann DA (2001) Medication errors and adverse drug events in pediatric inpatients. JAMA 285:2114-2120

40. Ross LM, Wallace J, Paton JY (2000) Medication errors in a paediatric teaching hospital in the UK: five years' operational experience. Arch Dis Child 83:492-497

41. Vincer MJ, Murray JM, Yuill A, Allen AC, Evans JR, Stinson DA (1989) Drug errors and incidents in a neonatal intensive care unit. AJDC 143:737-740
42. Kane SL, Weber RJ, Dasta JF (2003) The impact of critical care pharmacists on enhancing patient outcomes. Intensive Care Med 29:691-698

43. Bates DW, Gawande AA (2003) Improving safety with information technology. N Engl J Med 348:2526-2534

44. Fortescue EB, Kaushal R, Landrigan CP, McKenna KJ, Clapp MD, Federico F, Goldmann DA, Bates DW (2003) Prioritizing strategies for preventing medication errors and adverse drug events in pediatric inpatients. Pediatrics 111:722-729

45. Speidel BD (1978) Adverse effects of routine procedures on preterm infants. Lancet 1:864-866

46. Marik PE, Pinsky M (2003) Death by parenteral nutrition. Intensive Care Med 29:867-869

47. Bhutani VK, Abbasi S, Silvieri EM (1988) Continuous skeletal muscle paralysis: effect on neonatal pulmonary mechanics. Pediatrics 81:419-422

48. Fanconi S, Ensner S, Knecht B (1995) Effects of paralysis with pancuronium bromide on joint mobility in premature infants. J Pediatr 127:134-136

49. Bolton CF, Laverty DA, Brown JD, Witt NJ, Hahn AF, Sibbald WJ (1986) Critically ill polyneuropathy: electrophysiologic studies and differentiation from Guillain-Barré syndrome. J Neurol Neurosurg Psychiatry 49:563-573

50. Russell FM, Shann F, Curtis N, Mulholland K (2003) Evidence on the use of paracetamol in febrile children. Bull World Health Organ 81:367-372

51. Kamper J, Wulff K, Larsen C, Lindeqvist S (1993) Early treatment with nasal continuous positive airway pressure in very low birthweight infants. Acta Paediatrica 82:193-197

52. Han VK, Beverly DW, Clarson C (1987) Randomized controlled trial of very early continuous distending pressure in the management of preterm infants. Early Hum Dev 15:21-32

53. World Health Organisation (1993) Oxygen therapy for acute respiratory infections in young children in developing countries. World Health Organisation, Geneva WHO/ARI 93.28

54. Locke RG, Wolfson MR, Shaffer TH, Rubenstein SD, Greenspan JS (1993) Inadvertent administration of positive end-distending pressure during nasal cannula flow. Pediatrics 91:135-138

55. Frey B, McQuillan PJ, Shann F, Freezer N (2001) Nasopharyngeal oxygen therapy produces positive end-expiratory pressure in infants. Eur J Pediatr 160:556-560

56. Klein M, Reynolds LG (1989) Nasopharyngeal oxygen in children (letter). Lancet 1:493-494 
57. Amato MB, Barbas CS, Medeiros DM (1998) Effect of a protective-ventilation strategy on mortality in the acute respiratory distress syndrome. N Engl $\mathbf{J}$ Med 338:347-354

58. The Acute Respiratory Distress Syndrome Network (2000) Ventilation with lower tidal volumes as compared with traditional tidal volumes for acute lung injury in the acute respiratory distress syndrome. N Engl J Med 342:13011308

59. Gerstmann DR, Minton SD, Stoddard RA (1996) The Provo multicentre early high frequency oscillatory ventilation trial: improved pulmonary and clinical outcome in respiratory distress syndrome. Pediatrics 98:1044-1057

60. Rimensberger PC, Beghetti M, Hanquinet S (2000) "First intention" high-frequency oscillation (hfo) with early lung volume optimization improves pulmonary outcome in verylow-birth-weight infants with respiratory distress syndrome. Pediatrics 105:1202-1208
61. Teague WG (2003) Noninvasive ventilation in the pediatric intensive care unit for children with acute respiratory failure. Pediatr Pulmonol 35:418-426

62. Tasker RC, Boyd SG, Harden A, Matthew DJ (1990) The cerebral function analysing monitor in paediatric medical intensive care: applications and limitations. Intensive Care Med 16:6068

63. Macnab AJ, Gagnon RE, Gagnon FA (1998) Unresolved instrumentation problems following clinical trials using near infrared spectroscopy. J Biomed Optics 3:386-390

64. Tibby SM, Hatherill M, Murdoch IA (2000) Use of transesophageal Doppler ultrasonography in ventilated pediatric patients: derivation of cardiac output. Crit Care Med 28:2045-2050

65. Frey B, Losa M (2001) The value of capillary whole blood lactate for blood transfusion requirements in anaemia of prematurity. Intensive Care Med 27:222-227
66. Heitmiller ES, Wetzel RC (1996) Hemodynamic monitoring: considerations in pediatric critical care. In: Rogers MC (ed) Textbook of pediatric intensive care. Williams and Wilkins, Baltimore p 609

67. Hanning CD, Alexander-Williams JM (1995) Pulse oximetry: a practical review. BMJ 311:367-370

68. Frey B, Butt W (1998) Pulse oximetry for assessment of pulsus paradoxus: a clinical study in children. Intensive Care Med 24:242-246

69. Tamburro RF, Ring JC, Womback K (2002) Detection of pulsus paradoxus associated with large pericardial effusions in pediatric patients by analysis of the pulse-oximetry waveform. Pediatrics 109:673-677

70. Beckmann U, Baldwin I, Hart GK, Runciman WB (1996) The Australian incident monitoring study in intensive care: AIMS-ICU. An analysis of the first year of reporting. Anaesth Intensive Care 24:320-329 